\title{
A special issue in honour of Stephen Lea - a true comparative psychologist
}

\author{
Lisa Leaver $^{1}$ (D) Anna Wilkinson ${ }^{2}$ \\ Published online: 29 January 2020 \\ (C) The Psychonomic Society, Inc. 2020
}

It has been a privilege to be invited to edit this special edition of Learning \& Behavior to celebrate Stephen Lea's impressive scientific career. His academic life has already spanned over 50 years and is still going strong. Stephen began his $\mathrm{PhD}$ in 1967 at Cambridge University and took on his first RA job at the same institution in 1970. He accepted his post at the University of Exeter in 1976, where he worked his way up from Lecturer to become full Professor of Psychology in 1990, serving as Head of Department (twice!), Dean of the Faculty of Science and Deputy Vice-Chancellor of the University. Stephen retired from the University of Exeter in 2011, but he has continued to be a very active Emeritus Professor, including serving as Editor-in-Chief for Animal Cognition from 2011-2016.

Stephen was awarded the Research Award at the annual 26th annual meeting of the International Society for Comparative Cognition (CO3) in April 2019 to honour his "outstanding contribution to the study of comparative cognition in animals". As recipient of this reward, he was invited to deliver the Master Lecture and the Society organised a symposium in his honour, which included contributions from his former PhD students, research assistants and academic colleagues. The symposium, and this Special Issue that has arisen from it, highlighted the breadth of Stephen's influence across core areas of comparative cognition including imitation, inhibitory control, discrimination learning, foraging decisions, laterality and category learning. It also gave us a taste of the many species Stephen has worked with, including dogs, squirrels, mice, pigeons and people - the mark of a true comparative psychologist. Stephen's enthusiasm and curiosity to understand the mechanisms of learning and behaviour has

Lisa Leaver

1.a.leaver@exeter.ac.uk

1 Psychology, University of Exeter, Exeter, UK

2 School of Life Sciences, University of Lincoln, Lincoln, UK contributed to what might best be described as his "web" of research outputs.

Stephen's main research interests cover both animal cognition and economic psychology, focussing on concept discrimination and foraging decisions in birds and mammals as well as the psychology of money, money management and intertemporal choice in humans. Stephen's expertise has always extended beyond the bounds of his core research focus and he is also well known for his more varied areas of research including animal welfare, evolutionary psychology and, more recently, using his knowledge of economic psychology to understand Brexit. A core area of Stephen's work, and one that has had a profound influence on the field, is his work on perception and concept formation in pigeons (amongst other animals including many undergraduate students). He has a long history of studying diving birds from the UK coastline, particularly watching cormorants and shags from the clifftops of his beloved Lundy Island, where he has brought generations of students to learn about animal behaviour. He has also spent years investigating the cognitive processes behind oystercatcher foraging behaviour, and the cognition and learning involved in squirrel foraging and food caching behaviour. As such, he truly has made an outstanding contribution to the study of comparative cognition, and his legacy in the field will continue to influence new scientists and fields of study for years to come.

In addition to his remarkable scientific contribution, Stephen's support of other scientists is legendary; it has had a profound influence on them as individuals and sets an example to the field as a whole. He has provided unsurpassed levels of support and mentorship to students and colleagues. Despite being retired, Stephen is still involved with supervising student projects, attending field courses, and advising and collaborating with colleagues; none of which will come as a surprise to those who know Stephen.

This edition reflects the breadth of Stephen's scientific influence. Stephen has always championed the need to do research in both the laboratory and the field, something that was unusual when he embarked on it and something that is represented in this Special Issue. 
The research included in this edition truly spans the discipline. As with Stephen's research, there is a substantial focus on the mechanisms underlying perception, category and concept learning across species. There is also a flavour of behavioural economics, including a review exploring the influence of delay on reward valuation. This Special Issue also contains fundamental work examining the link between brain and behaviour from work investigating the impact of age on cognitive processing to the role that lateralisation plays in learning.

Stephen has always been interested in using models to understand mechanisms underlying apparently complex behaviours; this is exemplified by his work in this issue, which investigates the concept of behavioural flexibility and that of Lazareva and colleagues who investigate whether associative models can account for transitive inference observed in monkeys.

Stephen has also had a substantial influence on current hot topics in animal cognition including dog cognition, with a recent review of his suggesting that dogs did not display "exceptional" cognitive abilities when taken in the context of their evolution and ecology. However, a contribution to this Special
Issue looking at over-imitation in dogs suggests they may be somewhat special after all.

Stephen's work on pigeon perception has been enormously influential and this is reflected by the work in this Special Issue, which presents a wealth of research including action recognition, complex discriminations, inhibition and tracking behaviour. The comparative nature of Stephen's research programme is reflected in this Special Issue not just in the variety of species covered, from spiders to primates, but also in the fact that a number of the papers in this edition are aimed at elucidating both the shared and the distinct cognitive properties of birds versus mammals.

We feel that the breadth and variety of the work presented here really pays tribute to the enormous influence that Stephen has had on the field.

Publisher's note Springer Nature remains neutral with regard to jurisdictional claims in published maps and institutional affiliations. 